\title{
Experiências formativas com brincadeiras e interações na educação infantil
}

Alexandre Rodrigo Nishiwaki da Silva ${ }^{1}$

Resumo: Este artigo apresenta o Projeto "Organização do Tempo-Espaço na Educação Infantil", iniciativa desenvolvida a partir da demanda de formação de profissionais da Educação Infantil apresentada pela Secretaria Municipal de Educação e Cultura de Alfenas, Minas Gerais. Foram realizados encontros nas escolas, nos quais levantamos a forma como as brincadeiras são incorporadas à prática pedagógica em cada contexto, tendo como objetivo construir espaços em que a brincadeira e a interação estivessem na centralidade. O projeto se orienta por relações dialógicas entre a universidade e a comunidade, superando a hegemonia acadêmica e privilegiando a construção coletiva de saberes, ou seja, elaborar com as professoras da rede municipal um aparato teórico e prático sobre a importância da brincadeira e da interação nesta etapa da educação. Buscamos construir conhecimentos ética e cientificamente coerentes por meio da Metodologia Comunicativa Crítica, perspectiva que almeja não apenas explicar as situações sociais, mas edificar sonhos e utopias para transformar a sociedade. O referencial adotado, Aprendizagem Dialógica, em linhas gerais interpreta os problemas educativos e busca transpô-los por meio de práticas solidárias e igualitárias. Assim, este projeto se propõe a discutir as exigências da formação de professores/as para a educação infantil com a contribuição de diferentes perspectivas para, em diálogo com os/as docentes e a comunidade, construir novas propostas pedagógicas. Como resultados, apontamos o envolvimento das escolas nos processos de elaboração de novas práticas, reconfigurando a organização do espaço e do tempo, e centralizando a brincadeira e a interação no processo de ensino e aprendizagem na Educação Infantil.

Palavras-chave: Extensão Universitária; Formação Permanente de Professores/as; Creche; PréEscola

\section{Training experiences with play and interactions in childhood education}

Abstract: This paper presents the Project "Organization of time-space in Early Childhood Education," this initiative was developed based on the demand for training of Early Childhood Education professionals presented by the Education and Culture Secretariat of a municipality in the south of Minas Gerais State, Brazil. Meetings were held in schools in which we raised the way in which games are incorporated into pedagogical practice in each context, aiming to build spaces in which play and interaction were central. The project is guided by dialogical relations between the university and the community, overcoming academic hegemony and privileging the collective construction of knowledge, that is, building with the teachers a theoretical and practical apparatus on the importance of play and interaction in education childish. We seek to build ethical and scientifically coherent knowledge through Critical Communicative Methodology, a perspective that aims not only to explain social situations but to build dreams and utopias to transform society. The theory, Dialogical Learning, broadly interprets educational problems and seeks to overcome them through solidary and egalitarian practices. Thus, this project aims to discuss the requirements of teacher training for early childhood education with the contribution of different perspectives to, in dialogue with teachers and the community, develop new pedagogical proposals. As a result, we point out the involvement of schools in the processes of building new practices, reconfiguring the organization of space and time, and centralizing play and interaction in the process of teaching and learning in Early Childhood Education.

Keywords: University Extension; Permanent Teacher Training; Nursery; Pre-Schoo
Originais recebidos em

23 de abril de 2019

Aceito para publicação em

09 de abril de 2020

1

Doutor em Educação, Universidade Federal de Alfenas - UNIFAL-MG

Afiliação atual:

Departamento de Teorias e Práticas Pedagógicas (DTPP), Centro de Educação e Ciências Humanas (CECH), Universidade Federal de São Carlos - UFSCar alexandrerns@gmail.com 


\section{Introdução}

O Projeto "Organização do Tempo-Espaço na Educação Infantil" é desenvolvido pela Universidade Federal de Alfenas (UNIFAL) em parceria com a Secretaria Municipal de Educação e Cultura de Alfenas (SMEC), e nasce da demanda apresentada pela equipe de supervisão pedagógica da SMEC para a formação de profissionais da Educação Infantil no que tange à brincadeira e à interação das crianças. Atualmente, o município conta com 18 unidades de Educação Infantil, divididas em creches e pré-escolas e, até a publicação deste artigo, o projeto foi implementado e está sendo desenvolvido em 10 escolas, sendo que as demais unidades já têm calendário específico para a formação permanente e início das atividades.

As normativas dedicadas à Educação Infantil no Brasil, como as Diretrizes Curriculares Nacionais para a Educação Infantil (Ministério da Educação, 2010) e a Base Nacional Comum Curricular [BNCC] (Ministério da Educação, 2017), explicitam que a prática pedagógica com crianças pequenas deve, necessariamente, balizar suas ações na brincadeira e na interação. Nota-se, no entanto, que estes dois elementos se apresentam distantes da realidade das escolas alfenenses, conforme relato da própria equipe pedagógica da SMEC.

Permanece na rede municipal uma postura escolarizada das práticas educativas, revelada em atividades centradas na figura da professora, dentro das salas e com preenchimento de 'folhinhas', postura que, do nosso ponto de vista, ignora o protagonismo das crianças na aprendizagem. Diante deste quadro, tivemos a oportunidade de construir com as escolas de educação infantil momentos de formação sobre a importância do brincar e da interação, bem como analisar as peculiaridades de cada contexto. Além disso, propôs-se, em conjunto com as educadoras, a reorganização da prática pedagógica amparada nos estudos e legislações atuais, assegurando os direitos de aprendizagem (Ministério da Educação, 2017).

A educação infantil na sociedade contemporânea tem se configurado um campo de discussão que necessita de abordagens multidisciplinares, para que possamos compreender a infância enquanto construção social. Em nossas ações e investigações, privilegiamos as instituições educativas como locus de análise, sobretudo as creches e pré-escolas, reconhecendo os/as profissionais como agentes fundamentais. Os/as professores/as são, neste projeto, corresponsáveis pelo desenvolvimento do mesmo, construindo dialogicamente caminhos para a transformação da prática pedagógica, na direção do que apontam os trabalhos de Alarcão (2008) e Reis e Ostetto (2018) sobre a prática reflexiva.

No trabalho que ora apresentamos, nos orientamos, assim como preconizam as Diretrizes para a Extensão na Educação Superior Brasileira (Conselho Nacional de Educação, 2018), por relações dialógicas entre a universidade e a comunidade, ou seja, trata-se de vencer o enunciado da supremacia acadêmica e substituí-lo pela construção coletiva de saberes e práticas em torno do objetivo principal desta propostas: criar com as educadoras da rede municipal um aparato teórico e prático sobre a importância da brincadeira e da interação na educação infantil.

Dessa forma, o projeto apresenta uma resposta às exigências atuais da formação de professores/as para a educação infantil, a partir da contribuição de diferentes perspectivas para, em diálogo com os/as educadores/as e a comunidade, elaborar novas práticas e uma proposta pedagógica inovadora, reconfigurando a organização do espaço e do tempo e centralizando a brincadeira e a interação no processo de ensino e aprendizagem das crianças. Neste projeto, compreendemos a infância como possibilidade, como construtora de seu espaço-tempo, um lugar de experiência, ou seja, a educação infantil é lugar de potência e criação para as crianças e seus/suas professores/as. 


\section{Aprendizagem Dialógica e Metodologia Comunicativa Crítica como instrumentos de transformação social}

O desenvolvimento de relações dialógicas entre a universidade e a comunidade orientou este trabalho. $\mathrm{O}$ projeto buscou promover a cooperação e a democratização do conhecimento, colocando em evidência atores não-universitários em sua produção e difusão. Assim, discutimos as necessidades contemporâneas da formação de professores/as para a educação infantil a partir da colaboração de diversas perspectivas, em diálogo com os/as educadores/as e a comunidade, promovendo uma nova proposta pedagógica para as creches e pré-escolas do município.

Desta forma, discutimos não apenas as especificidades que compõem a Educação Infantil, mas como cada uma delas contribui para o estabelecimento de práticas pedagógicas condizentes com as necessidades da sociedade atual. Nesta direção, Rosseti-Ferreira et al. (2009) sinalizam que

Visões teórico-metodológicas contribuem para construir realidades sociais que podem, por sua vez, influir, modificar e ampliar/restringir o desenvolvimento e a qualidade de vida das pessoas, podendo muitas vezes até inseri-las em um movimento de exclusão. As teorias, em função de seus pressupostos, consolidam formas não só de compreender e estudar os processos desenvolvimentais, como também elas constituem as relações que lhes darão suporte e as práticas profissionais que incidirão sobre elas. (p. 438)

A partir da revisão dos conceitos centrais da educação infantil que realizamos nos encontros de formação permanente com as/os educadoras/es, nos esforçamos na elaboração de um conhecimento ético e cientificamente coerente. Para tanto, lançamos mão da Metodologia Comunicativa Crítica (MCC) (Gómez et al., 2006). Esta metodologia, que é por definição dialógica, pretende não apenas explicar e entender as situações sociais, mas construir sonhos, utopias e ações para transformar a sociedade. Sua contribuição reside justamente em aliar os conhecimentos acadêmicos e possibilidades reais de transformação com os sujeitos envolvidos nos processos sociais.

O referencial teórico utilizado pelo projeto em questão é o da Aprendizagem Dialógica que, amparado nas principais teorias e investigações científicas em âmbito internacional, com enfoque interdisciplinar, analisa os desafios educacionais e busca alternativas para superá-los (Aubert et al., 2018). A partir de uma consistente crítica ao contexto social atual, marcado pelas complexas relações sociais da chamada Sociedade da Informação, a Aprendizagem Dialógica propõe a construção de práticas solidárias e igualitárias.

Para melhorar nossa educação, é necessária muita boa vontade, mas isso não é o suficiente; é preciso que as propostas feitas não sejam somente produto de boa intenção, mas também de uma intenção suficientemente boa que inclua o esforço pela busca de atuações com resultados melhores (Aubert et al., 2018, p. 194).

$\mathrm{Na}$ Aprendizagem Dialógica os argumentos devem ser baseados em pretensões de validade, superando os fundamentados em posicionamentos de poder. Isso significa que as relações no interior das escolas e fora dela devem estar ancoradas em ações comunicativas, nas quais as tomadas de decisão são fruto do diálogo entre todos/as os/as envolvidos/as no processo, uma vez que todas as pessoas podem refletir sobre a própria vida e o contexto social, para transformá-lo. No processo de formação permanente que promovemos por meio deste projeto, nos esforçamos em garantir em cada encontro, não apenas um clima acolhedor para que as professoras pudessem refletir e discutir a prática, mas, principalmente, legitimamos e validamos seus argumentos enquanto exercício da racionalidade comunicativa. 
Para Gómez (2004), a escola é elemento muito importante na Sociedade da Informação, já que pode possibilitar uma nova forma de socialização, a dialógica. Nesta direção, o autor apresenta quatro pontos fundamentais: (a) a radicalização da democracia, (b) o protagonismo social, (c) o diálogo e o consenso e, por fim, (d) o reencanto na comunicação. $O$ mesmo autor defende que a sociedade atual promove a construção das relações em estruturas completamente diferentes, que se pautam na busca pela horizontalização, abrindo caminho para a efetivação de uma educação solidária e dialógica.

Segundo Mello et al. (2012), a Aprendizagem Dialógica é um paradigma conceitual que origina uma forma transformadora de aprendizagem e interação em torno da superação das desigualdades sociais, na escola e fora dela, a partir de sete princípios: (1) Diálogo igualitário: corresponde à comunicação centrada na pretensão de validez, na argumentação racional, evitando o discurso baseado na posição de poder de quem fala e sua colocação na hierarquia social (Mello et al., 2012); (2) Inteligência Cultural: este princípio enuncia a competência argumentativa de todos e todas diante de um contexto social compartilhado, valorizando as contribuições de diferentes grupos para a compreensão dos problemas sociais (Aubert et al., 2018); (3) Transformação: a Aprendizagem Dialógica tem como objetivo a transformação das relações e do contexto social por meio do diálogo e do consenso (Mello et al., 2012,); (4) Dimensão Instrumental: os saberes validados socialmente são a base para a edificação de uma sociedade mais democrática (Gómez, 2004) e tornam os sujeitos capazes de examinar criticamente o contexto social para transformá-lo (Aubert et al., 2018); (5) Criação de Sentido: a Aprendizagem Dialógica aponta a criação de novos sentidos, novos significados e novos valores, capazes de auxiliar a busca de relações democráticas (Gómez, 2004), ancorado em concepções solidárias e igualitárias, na construção de consensos e na constituição de grupos que compartilham e se apoiam mutuamente (Aubert et al., 2018); (6) Solidariedade: a formação de práticas solidárias é um ponto nevrálgico na construção de relações democráticas, na luta pela liberdade de todos e todas (Mello et al., 2012); (7) Igualdade de Diferenças: para a Aprendizagem Dialógica, a igualdade não se sobrepõe à diferença, reconhecemos a igualdade enquanto um valor para todos e todas, assim como proclamamos o igual direito de ser diferente (Aubert et al., 2018).

Aprendizagem Dialógica coloca aos/às professores/as o compromisso com a elaboração de práticas pedagógicas cada vez mais igualitárias e solidárias. Nesta direção, não se pode pensar a transformação da escola e da sociedade sem a reflexão e o aprofundamento teórico, ou o que Freire (2008) chama de práxis, exigências do novo contexto social. Julgamos que os sete princípios da Aprendizagem Dialógica apontam caminhos para uma educação capaz de superar desigualdades sociais e favorecer a construção de uma sociedade mais democrática, objetivo perseguido por este projeto.

\section{Formação Permanente de Professores/as para a Educação Infantil: A experiência de um projeto de extensão}

O projeto "Organização do Espaço-Tempo na Educação Infantil" nasceu de demanda da SMEC, diante da avaliação da equipe de supervisão da educação infantil, sobre a escolarização precoce e disciplinarização das práticas pedagógicas desenvolvidas na rede, resultado de muitos anos de trabalho baseado em apostilas, material que foi retirado da rede em 2018. Após a apresentação da problemática pela secretaria, construímos coletivamente um projeto de formação permanente a ser desenvolvido para e com as professoras, sendo assumido pelo município enquanto uma proposta para todas as unidades escolares.

Este contexto explicita o apontado por Aquino (2015): o discurso dominante da "pré-escola" como etapa preparatória para a escolaridade do ensino fundamental, antecipando conteúdos e dando ênfase à alfabetização das crianças na educação infantil, o que contraria o acúmulo da discussão das pesquisas da área e a própria legislação. 
Vale salientar que a discussão realizada nesta seção é fruto de reflexão com as equipes das escolas e da universidade, formada inicialmente por dois docentes do Curso de Licenciatura em Pedagogia e 12 estudantes do mesmo curso, tendo como fonte os registros do professor universitário coordenador do projeto, organizados em Diário de Campo. Por se tratar de um relato, além da percepção do professor universitário sobre cada etapa, resgatamos as vozes das profissionais das unidades de educação infantil que participaram do projeto.

O primeiro passo para a consolidação do projeto foi dialogar com as coordenações das escolas sobre as necessidades formativas para a docência na Educação Infantil. Este encontro foi bastante importante, porque nos permitiu a ampliação da compreensão que tínhamos da rede, a partir dos relatos apresentados pelas coordenadoras e diretoras de cada escola do município, revelando, de um lado, contextos singulares, e de outro, questões bastante comuns.

Com as coordenadoras e gestoras, definimos um Plano de Ação, as escolas prioritárias e as melhores formas de intervenção (Figura 1). Decidimos que as professoras deveriam ter momentos de formação teórica e experiências práticas, o que nos levou a optar por desenvolver o projeto por períodos mais longos do que o incialmente proposto. Passaríamos dois meses em cada escola com encontros semanais nos momentos de formação permanente, e ao longo da rotina das escolas, para conhecermos as experiências práticas.

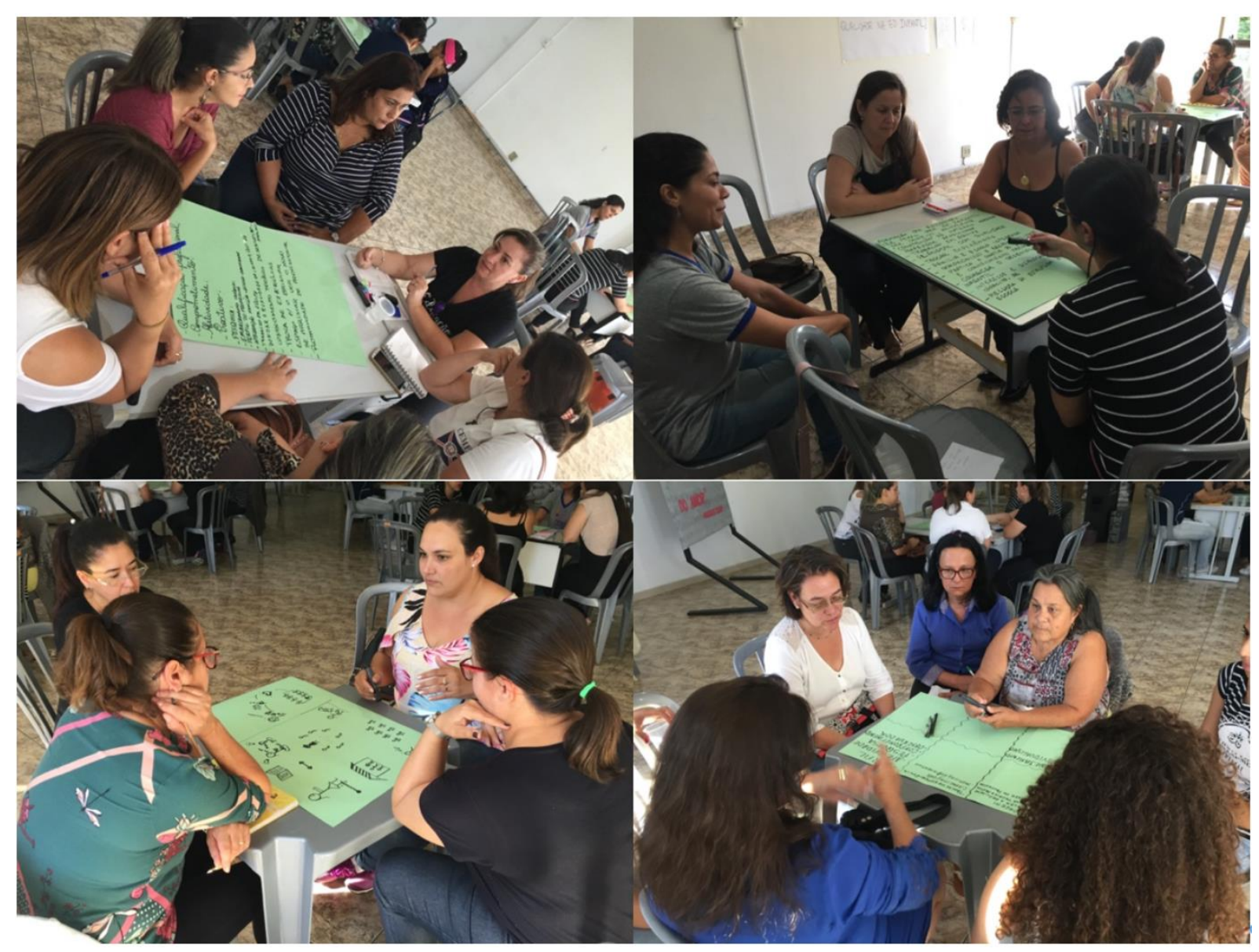

Figura 1. Reunião com as Equipes de Coordenação Pedagógica das escolas, destinadas à elaboração do Plano de Ação, e definição das escolas prioritárias e as melhores formas de intervenção. 
Por sugestão das coordenadoras e diretoras, desenhamos um tipo de acompanhamento não previsto: as equipes de coordenação das demais unidades participariam de todas as formações em todas as escolas, para fortalecer a compreensão do projeto e colaborar com o desenvolvimento em suas próprias escolas. Além disso, de acordo com nosso Plano de Ação, algumas escolas demorariam muito tempo para receber o projeto e, com as equipes gestoras formadas, seria possível antecipar a realização. Este movimento nos pareceu bastante interessante, pois expôs um espírito de comprometimento coletivo e, acima de tudo, possibilitou trocas de experiências que estão para além do discurso monolítico que, muitas vezes, a universidade professa.

O projeto foi apresentado em cada uma das escolas participantes nas reuniões de "Módulo", encontros realizados semanalmente em cada unidade da rede municipal para planejamento e formação permanente (Figura 2). Nesta ocasião, foram expostos os pressupostos teóricos e metodológicos do projeto e estabelecemos acordos coletivos entre a equipe executora e as profissionais da escola. A participação de todos/as os/as profissionais, professoras, auxiliares educacionais, equipe de cozinha e limpeza, manutenção patrimonial, entre outros, foi fundamental para garantir o desenvolvimento da proposta, uma vez que a compreensão sobre a infância, as brincadeiras e as interações influenciam diretamente o trabalho de toda comunidade escolar.

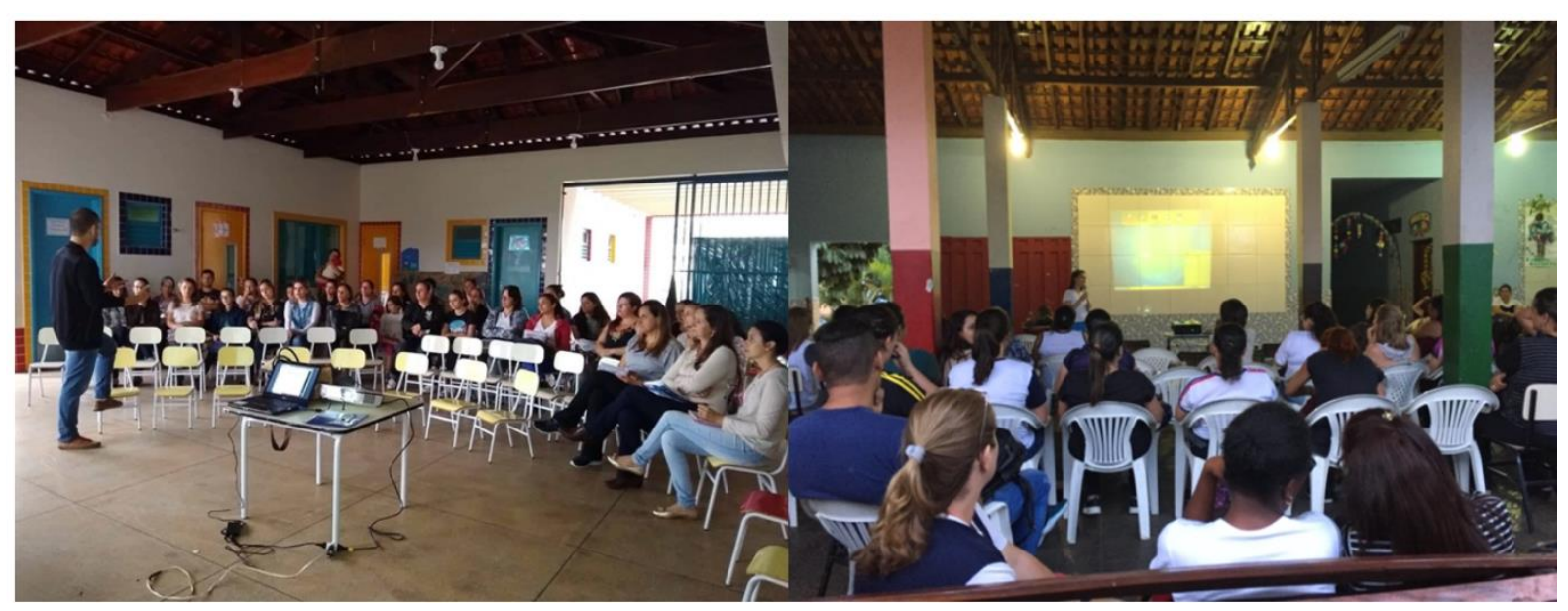

Figura 2. Reunião de Apresentação do Projeto "Organização do Espaço-Tempo na Educação Infantil" em duas das escolas nas quais foi desenvolvido.

Nesta etapa, explicitamos que a brincadeira é uma experiência complexa que envolve corpo, linguagem e rotinas de brincar, buscando discutir como essa experiência se realiza para as crianças em sua plenitude e o papel do adulto, tendo em vista a sua participação direta na organização das brincadeiras (Ferreira, 2004). Dialogamos com as equipes que a "brincadeira é um lugar de esforço criativo e contínuo, em que os participantes têm que se organizar coletivamente, de modo a conjugar experiências ainda não conhecidas" (Spréa, 2010, p. 225). Assim, a brincadeira se configura como o locus da infância, a possibilidade de estar com o outro, de se relacionar com ele e de construir conhecimentos.

Durante as apresentações nas escolas, percebemos que as equipes reconheciam a importância da brincadeira e da interação. Por outro lado, notamos que, no cotidiano, estes elementos estavam restritos aos momentos de parque e 'tempo livre', não sendo planejados intencionalmente.

Nos encontros seguintes, avaliamos a forma como a prática pedagógica estava organizada, como os tempos e os espaços de brincadeira e interação aconteciam e quais os desafios da escola. É importante reconhecer que as professoras, preocupadas com o 'pedagógico', denotavam à brincadeira um espaço secundário no 
planejamento. Muitas vezes a demanda se apresentava em questões do tipo: como incluir a brincadeira sem deixar que as crianças aprendem letras e números, ou, como garantir que as crianças estejam preparadas para o primeiro ano se elas 'só brincam'?

Neste momento, dialogamos sobre os caminhos e as expectativas de aprendizagem que cada escola desenvolve, seu projeto pedagógico e a forma como sua concepção de infância "toma vida". O processo de avaliação de cada escola, que ocorreu em diferentes momentos, é fundamental para o projeto, uma vez que, ancorados na perspectiva dialógica (Aubert et al., 2018), compreendemos que as pessoas diretamente envolvidas no processo de educação das crianças têm plenas condições de avaliar seu contexto e buscar alternativas viáveis para a melhoria da prática pedagógica .

Para organizar o diálogo, dividimos as professoras e distribuímos questões norteadoras: Quanto tempo as crianças brincam na creche/pré-escola? Quais os principais obstáculos para as brincadeiras? Como podemos superar esses obstáculos?

Após a discussão, os grupos compartilhavam uma síntese. De posse deste material, discutíamos com as professoras como a brincadeira e a interação poderiam assumir o protagonismo na prática pedagógica. Houve falas sobre os limitantes arquitetônicos (falta de espaço aberto e com sombra, muitas escadas, falta de parque), a escassez de materiais, a rotina muito controlada e a inexistência de planejamento coletivo, que foram apontados como elementos que impossibilitam as brincadeiras.

Sobre cada um destes pontos, pensamos possíveis alternativas para superá-los: buscar autorização para o fechamento da rua em frente à escola, utilizar os parques e praças do bairro, pesquisar materiais não estruturados que possam substituir os materiais comprados, solicitar acompanhamento por parte da SMEC e da equipe da escola para aperfeiçoar os planejamentos, entre outros.

Como contribuição da universidade, sugerimos organizar semanalmente momentos de brincadeiras e interações com todas as crianças da escola, diversificando as propostas já oferecidas, e possibilitando que crianças de diferentes idades possam brincar juntas. Consideramos que esta organização do espaço e do tempo nas creches e pré-escolas favorece a superação da escolarização, representada, sobremaneira, pela seriação das crianças por faixa etária. Além disso, como afirmamos em nosso referencial, a diversidade é um elemento potencializador das aprendizagens (Aubert et al., 2018), assim, quanto maior a diversidade, maior a possibilidade de desenvolvimento das crianças.

Realizamos o planejamento coletivo das oficinas de brincadeira e interação, e estas foram construídas em conjunto com as professoras e demais profissionais, como alternativa à segregação das práticas na educação infantil. Como exemplo de oficinas, podemos citar as oferecidas com foco nos bebês; oficinas sensoriais, com tintas comestíveis de diferentes cores e texturas, tinham como público principal os berçários, mas também deveriam incluir as crianças maiores. As professoras refletiram sobre o que as oficinas sensoriais podem provocar em todas as crianças, e quais relações os bebês teriam com os mais velhos, por meio da interação planejada intencionalmente.

As oficinas utilizavam os espaços disponíveis nas creches e pré-escolas, respeitando os combinados já estabelecidos, como horários de sono e refeições. A organização e a divisão dos espaços, bem como a quantidade de apoio em cada oficina, foram acordadas coletivamente. Cada uma das oficinas planejada era compartilhada com todo o grupo de professoras, e muitas sugestões foram sendo apresentadas. Planejar coletivamente pode ampliar o olhar docente sobre as ações, e contribuir para melhorar a prática de todos/as. O movimento coletivo e dialógico provocou um novo tipo de comportamento nas escolas, superando a ideia de 'minha sala, minhas crianças' para 'as crianças são da escola', e todos/as somos responsáveis por garantir uma educação de qualidade. Além disso, alguns obstáculos apresentados inicialmente, como a falta de material, foram superados com a colaboração e solidariedade de todos/as. 
Concordamos com Reis e Ostetto (2018) quando afirmam que a formação é uma síntese de experiências e conhecimentos apropriados antes e durante a formação inicial e/ou permanente. Podemos destacar, como elemento formativo, a profunda discussão que fizemos sobre cada uma das propostas planejadas pelas professoras. Em cada oficina, analisamos o que as crianças poderiam aprender, quais os objetivos, como seria desenvolvida a atividade e qual o papel da professora na mediação. Oficinas de artes plásticas, de movimento, de dança, de contação de histórias, brincar de casinha, explicitaram sua intencionalidade a partir do diálogo.

A partir do planejamento realizado coletivamente, as escolas foram convidadas a executá-lo com o acompanhamento da equipe da universidade, que teve condições objetivas de compreender a prática pedagógica e a cultura institucional de cada unidade. Foram realizados registros (fotos e filmagens) que seriam utilizadas na etapa seguinte. Durante aproximadamente 1 hora e 30 minutos, crianças experimentaram novas formas de brincar e organizar a rotina (Figura 3).

Ao longo de duas semanas, as professoras organizaram as oficinas que seriam desenvolvidas com várias turmas. A proposta era possibilitar que as crianças escolhessem a brincadeira com autonomia e que as professoras se responsabilizassem pelas oficinas, deixando suas turmas livres para circular pelo espaço. Assim, cada educadora mediava a relação de diversas crianças, provocando uma série de novas interações, diferentes das que as crianças tinham cotidianamente.

Ao considerarmos as crianças enquanto sujeitos em desenvolvimento, sua brincadeira se estrutura na medida em que acontece, com base no que é capaz de fazer em cada momento da vida. Se a criança tem seis meses ou três anos, apresenta diferentes possibilidades de comunicação e relação com os outros. Durante seu desenvolvimento, portanto, elas constroem novas e diferentes aprendizagens com os/as parceiros/as, no contexto das brincadeiras, que lhes permite compreender e atuar de forma mais ampla no mundo (Queiroz et al., 2006).

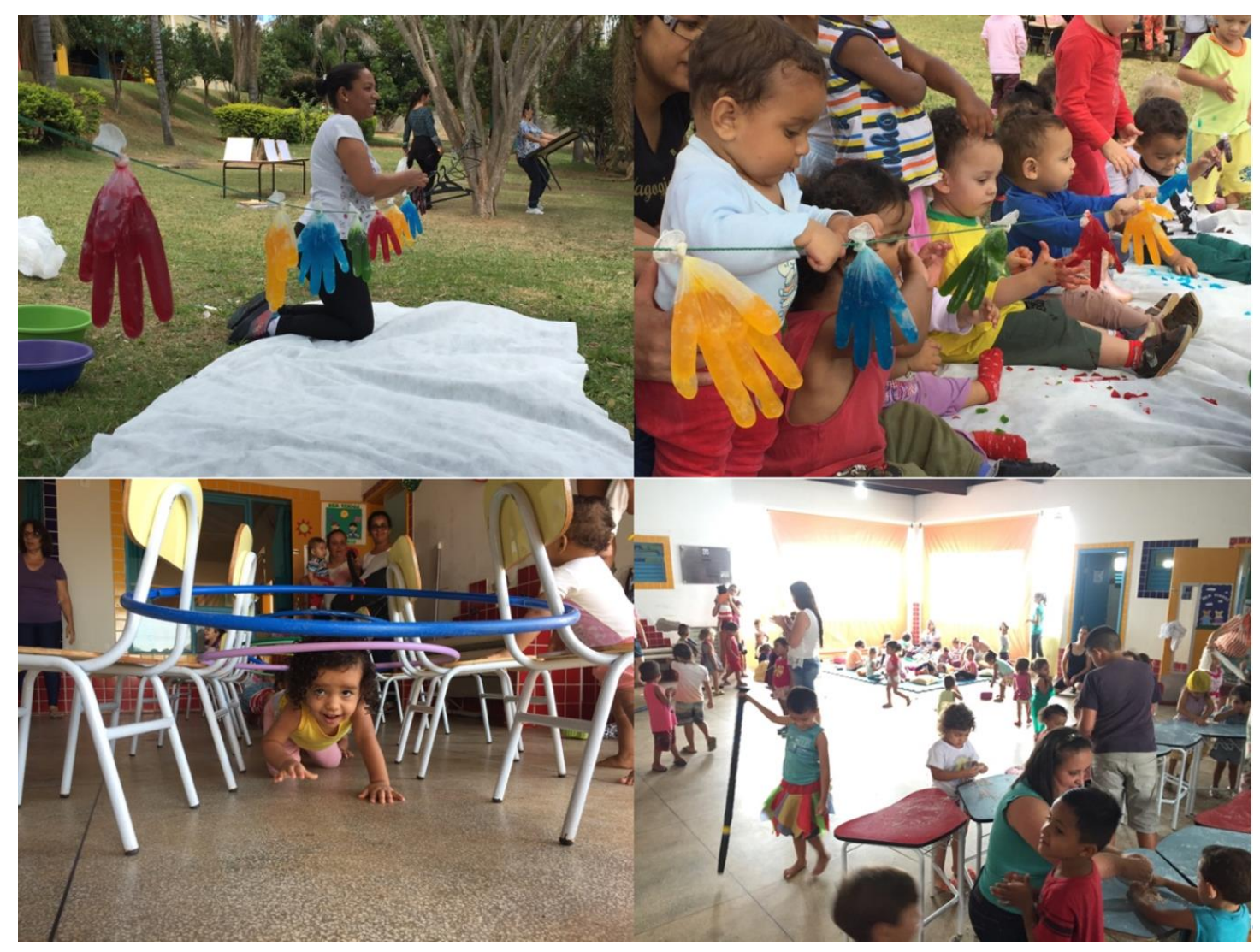

Figura 3. Organização e Execução do Planejamento das brincadeiras realizadas durante a execução do projeto em diferentes Creches e Pré-Escolas. 
Percebemos que, inicialmente, as professoras apresentaram certa insegurança com a proposta, pois deixar as crianças escolherem as brincadeiras, em diferentes espaços, com diferentes adultos, não era algo que estava consolidado. No entanto, ainda durante as oficinas, a tranquilidade com que as crianças exerceram sua autonomia revelou às professoras a necessidade de ampliar as expectativas em relação às possibilidades que os/as pequenos/as têm em se relacionar e mediar conflitos.

A equipe da universidade e as coordenadoras de cada unidade escolar, a partir das observações e dos registros realizados, se dedicaram à análise do desenvolvimento das atividades propostas, ressaltando elementos positivos e apresentando possibilidades de qualificação da prática desenvolvida.

Durante o processo de avaliação (Figura 4), dialogamos sobre as aprendizagens das crianças, os procedimentos metodológicos adotados, as interações e os avanços conceituais. Foi possível destacar as experiências proporcionadas às crianças, a forma como as mesmas interagiram com o espaço, com as mais novas, com as mais velhas e com os adultos. Com a avaliação, nos esforçamos em explicitar as potencialidades das crianças, articulando conhecimentos sobre o desenvolvimento infantil, a prática pedagógica e os campos de experiências previstos na BNCC (Ministério da Educação, 2017).

Demos, na avaliação, especial atenção ao não dito, à linguagem não verbal, ao sorriso de cada criança, à postura das educadoras diante dos desafios. Analisamos coletivamente o espaço das brincadeiras, a disposição dos brinquedos, a organização das crianças, seus desejos e preferências. Foi possível, no diálogo com as professoras, perceber a ampliação da sensibilidade do olhar para as crianças, e não sobre elas, enquanto sujeitos completos, plenos e capazes de assumir o protagonismo dos processos educativos.

De nossa perspectiva, amparados em Bondioli e Savio (2013), afirmamos que a avaliação na educação infantil se configura enquanto um processo autorreflexivo, negocial, transformativo e participativo-democrático. Não se trata de apontar as falhas do trabalho das professoras, tampouco normatizar a ação docente por meio de regras oriundas da universidade, mas construir esforços reflexivos que tenham como objetivo a melhoria da prática pedagógica para e com as crianças.

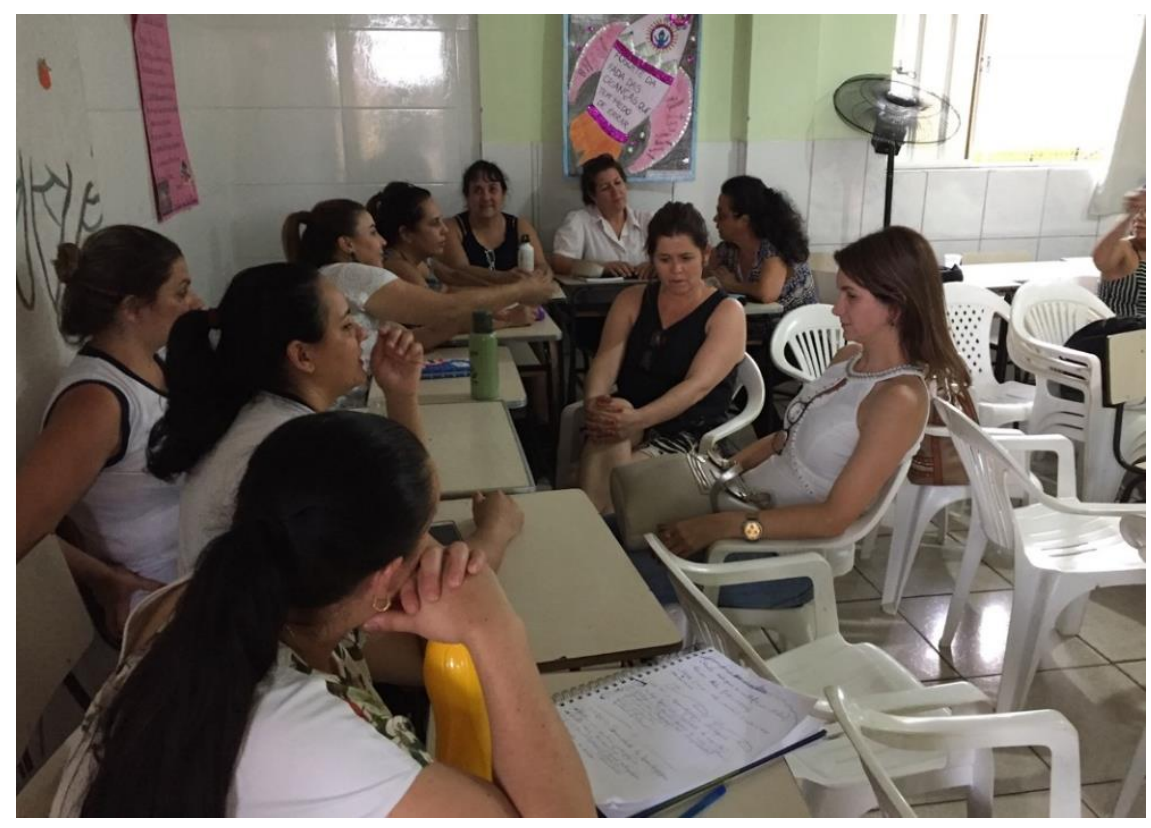

Figura 4. Reunião com a Equipe de uma das escolas para avaliação e reelaboração das atividades desenvolvidas ao longo do projeto. 
Inevitavelmente alguns conflitos aconteceram na avaliação, a sensação de desordem com o corre-corre das crianças, o tempo necessário para a preparação das oficinas, o trabalho de reorganizar o espaço utilizado, a sujeira, etc. Tudo isso foi também discutido enquanto elementos da educação infantil, a necessidade de nos assumirmos enquanto professores/as brincantes.

Após a avaliação, foi possível replanejar as oficinas, a metodologia, os caminhos percorridos e propor novas possibilidades, tendo como perspectiva a brincadeira e a interação, enquanto foco educativo no âmbito das instituições de educação infantil (Ministério de Educação, 2010). Para isso, solicitamos que as professoras discutissem coletivamente os pontos positivos da atividade e, em seguida, os negativos, e as possíveis soluções para superar as dificuldades apresentadas. Feita a avaliação geral de todo processo, construímos com as unidades escolares as melhores formas de continuar as oficinas, a periodicidade, a relação com a universidade e os instrumentos para a conquista da autonomia da escola.

Para finalizar o primeiro ano do projeto, a SMEC sugeriu o $1^{\circ}$ Encontro Municipal de Educação Infantil com todas as profissionais da rede para compartilharmos as experiências. Em um sábado letivo de agosto de 2019, as 400 educadoras da rede ocuparam as dependências da universidade para apresentarem suas brincadeiras (Figura 5).

Iniciamos o encontro apresentando um documentário produzido pelos/as estudantes do Curso de Pedagogia, com imagens e depoimentos coletados durante a realização do projeto. O filme emocionou as participantes do encontro, que se sentiram protagonistas de sua própria prática. Após o momento coletivo, as professoras foram divididas em salas, sempre garantindo a maior variedade de escolas e faixas etárias, para apresentarem seus trabalhos.

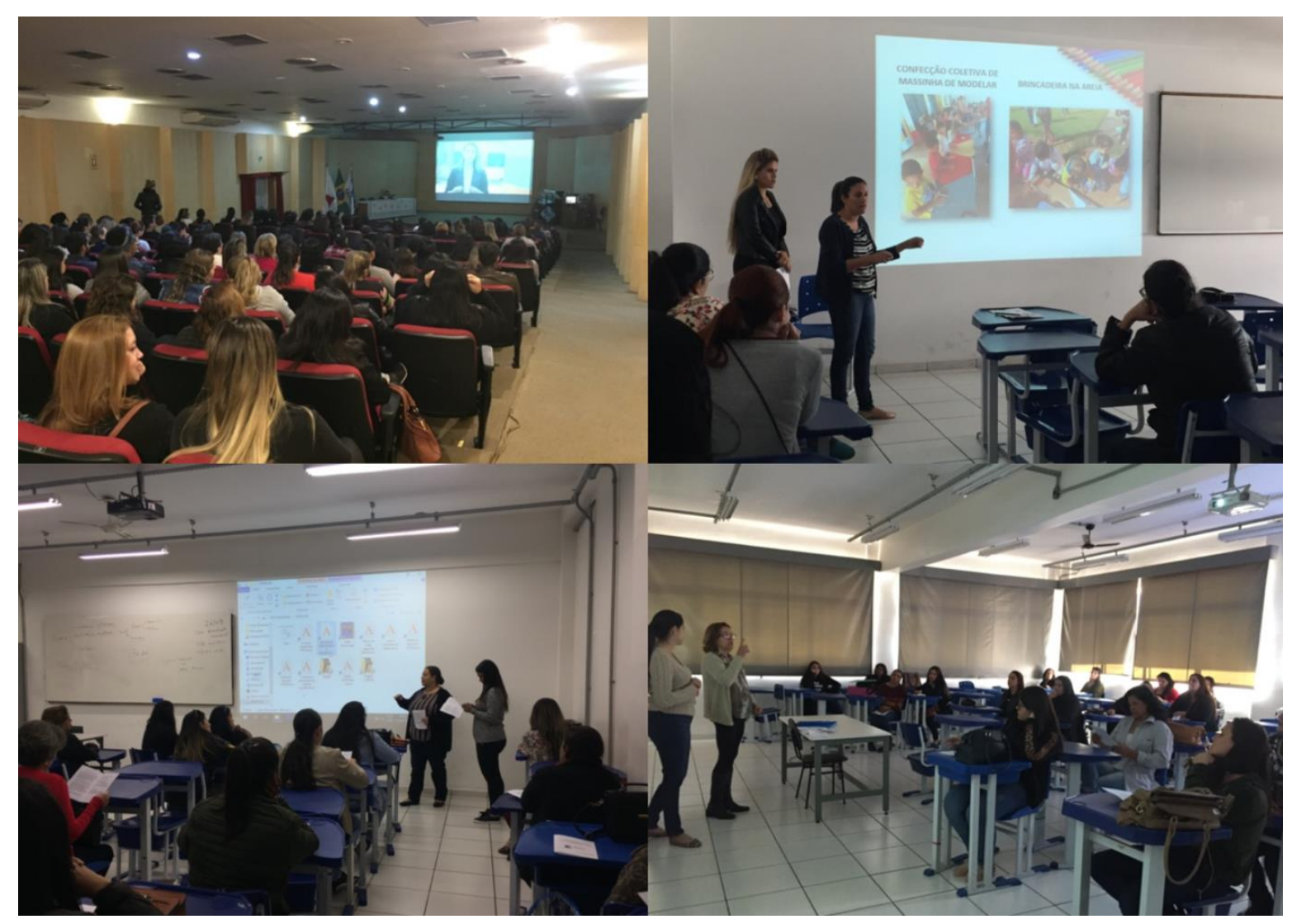

Figura 5. Atividades do $1^{\circ}$ Encontro Municipal de Educação Infantil: abertura no Auditório "Dr. João Leão de Faria" (UNIFAL-MG) e apresentação dos trabalhos desenvolvidos pelas professoras durante o projeto. 
Por meio de imagens, registros e muitas reflexões sobre a própria prática, as professoras explicitaram as brincadeiras que têm proposto, os objetivos de cada uma, os materiais que utilizam, as leituras que realizam, as dificuldades que encontram. Este momento, além de muito prazeroso, possibilitou que ampliassem o repertório de práticas, avaliassem coletivamente o trabalho e, acima de tudo, assumissem o caráter intelectual da prática pedagógica.

Percebemos no $1^{\circ}$ Encontro o que Vygotsky (1998), um dos mais importantes representantes da psicologia histórico-cultural, teorizou: que o sujeito se constitui nas relações com os outros, por meio de atividades caracteristicamente humanas, que são mediadas por ferramentas técnicas e semióticas.

Neste projeto, a brincadeira e a interação ocupam uma posição privilegiada para a análise do processo de constituição do sujeito, superando a visão de que ela é uma atividade banal e corriqueira de satisfação de desejos infantis. Resgatando mais uma vez as contribuições de Vygotsky (1998), o brincar é uma atividade em que, tanto os significados social e historicamente produzidos são construídos, quanto novos podem emergir. A brincadeira e a interação, que são consideradas como espaços de construção de conhecimentos pelas crianças, o foram igualmente para as professoras, na medida em que os significados que ali transitam são apropriados também por elas.

\section{Considerações Finais}

O projeto "Organização do Espaço-Tempo na Educação Infantil" tem como objetivo contribuir para a formação permanente das professoras da rede municipal de Alfenas e construir coletivamente práticas pedagógicas para a Educação Infantil, centralizadas no binômio brincadeiras e interações. Buscamos auxiliar as educadoras a refletirem sobre estes elementos em seu exercício profissional, formulando coletivamente alternativas para a efetivação de uma prática pedagógica que garanta os direitos assegurados às crianças.

As normativas que regulam a Educação Infantil no Brasil apontam a brincadeira e a interação como centrais para a prática pedagógica dedicada à infância. Estes dois elementos representam principal ponto de apoio para o desenvolvimento infantil. Por outro lado, nota-se que as instituições educativas reproduzem práticas 'escolarizadas', que ignoram as peculiaridades da educação para a primeira infância, como relatado pela equipe da SMEC.

Nos encontros presenciais com as escolas de Educação Infantil, avaliamos as atividades já realizadas em cada unidade. Neste momento, as professoras puderam apresentar a forma com desenvolvem suas práticas, refletindo coletivamente formas de potencializar o desenvolvimento das crianças, por meio do conhecimento de teorias contemporâneas, como a Aprendizagem Dialógica (Aubert et al., 2018).

Foi nesta direção que caminhou este projeto: cada escola, a partir da reflexão teórica, da análise do contexto e da avaliação das práticas desenvolvidas, promoveu autonomamente novos planejamentos, superando ações baseadas no senso comum, e construindo um aparato próprio de instrumentos pedagógicos.

O projeto possibilitou diversas reflexões, dentre as quais destacamos: (a) repensar a formação permanente de professores/as a partir do amplo diálogo (docentes universitários/as, professores/as e gestores/as da rede municipal); (b) questionar a estrutura disciplinar na formação do/a professor/a; (c) repensar a formação de professores/as da Educação Infantil a partir de princípios dialógicos e democráticos; (d) possibilitar a construção da identidade docente e impactar na qualidade da escola pública; (e) ampliar a compreensão da própria escola como espaço formativo.

Por fim, concluímos que o projeto promoveu a análise da prática pedagógica desenvolvida e buscou configurála com base na centralidade da brincadeira e da interação. Sabe-se que muitas escolas continuam reproduzindo práticas 'escolarizadas' que desconfiguram a especificidade da Educação Infantil. Este projeto 
auxiliou as educadoras da infância a compreenderem a importância da brincadeira e da interação para o seu exercício profissional, discutindo coletivamente alternativas para a implementação de uma prática pedagógica respaldada na legislação nacional e no debate teórico atual.

\section{Referências}

Alarcão, I. (2008). Professores reflexivos em uma escola reflexiva. 6. ed. São Paulo: Cortez.

Aquino, L. M. L. D. (2015). Contribuições da teoria histórico-cultural para uma educação infantil como lugar das crianças e infâncias. Fractal: Revista de Psicologia, 27(1), 39-43.

Aubert, A., Flecha, A., García, C., Flecha, R., \& Racionero, S. (2018). Aprendizagem dialógica na Sociedade da Informação. São Carlos: EdUFSCar.

Bondioli, A., Savio, Da. (2013). Participação e qualidade em educação da infância: Percursos de compartilhamento reflexivo em contextos educativos. Curitiba: Editora da UFPR.

Conselho Nacional de Educação. Brasil. (2018). Diretrizes para a Extensão na Educação Superior Brasileira. Câmara de Educação Superior. Brasília: CNE. Recuperado de: http://portal.mec.gov.br/ index.php?option=com docman\&view=\%20download\&alias=104251-rces007-18\&category slug=dezembro-2018pdf\&Itemid $=30192$

Ferreira, M. M. M. (2004). Do "avesso" do brincar ou... as relações entre pares, as rotinas da cultura infantil e a construção da(s) ordem(ens) social(ais) instituintes(s) das crianças no Jardim-de-Infância. In M. Sarmento \& A. Ceresara (Orgs.), Crianças e miúdos: Perspectivas sociopedagógicas da infância e educação. (pp. 55-104). Porto: ASA.

Freire, P. (2008). Pedagogia do Oprimido. Rio de Janeiro: Paz e Terra. 47. Edição.

Gómez, J. (2004). El amor en la sociedad del riesgo. Una tentativa educativa. Barcelona: El Roure.

Gómez, J., Latorre, A., Sánchez, M. \& Flecha, R. (2006). Metodología Comunicativa Crítica. Barcelona: El Roure.

Mello, R. R., Braga, F. M. \& Gabassa, V. (2012). Comunidades de Aprendizagem: Outra escola é possível. São Carlos: Editora da Universidade Federal de São Carlos.

Ministério da Educação. Brasil. (2010). Diretrizes curriculares nacionais para a educação infantil. Brasília: MEC, Secretaria de Educação Básica (SEB). Recuperado de: http://ndi.ufsc.br/files/2012/02/Diretrizes-Curriculares-para-a-El.pdf

Ministério da Educação. Brasil. (2017). Base Nacional Comum Curricular. Brasília: MEC, Secretaria de Educação Básica (SEB). Recuperado de: http://basenacionalcomum.mec.gov.br/images/BNCC El EF 110518 versaofinal site .pdf

Queiroz, N. L., Maciel, D. A. \& Branco, A. U. (2006). Brincadeira e desenvolvimento infantil: Um olhar sociocultural construtivista. Paidéia, 16(34), 169-179. Recuperado de: https://doi.org/10.1590/S0103-863X2006000200005

Reis, G. \& Ostetto, L. (2018). Compartilhar, estudar, ampliar olhares: Narrativas docentes sobre formação continuada. Educação e Pesquisa, 44, e180983.

Rossetti-Ferreira, M. C., Amorim, K. \& Oliveira, Z. (2009). Olhando a criança e seus outros: Uma trajetória de pesquisa em educação infantil. Revista de Psicologia USP, 20(3), 437-464.

Spréa, N. E. (2010) A invenção das brincadeiras: Um estudo sobre a produção das culturas infantis nos recreios de escolas em Curitiba (Dissertação de Mestrado). Universidade Federal do Paraná, Curitiba, Brasil. Recuperado de: https://acervodigital.ufpr.br/bitstream/handle/1884/56182/R\%20-\%20T\%20-

\%20NELIO\%20EDUARDO\%20SPREA.pdf?sequence $=1$ \&isAllowed $=y$

Vygotsky, L. (1998). A formação social da mente. São Paulo: Martins Fontes.

Como citar este artigo:

Nishiwaki da Silva, A. R. (2020). Experiências formativas com brincadeiras e interações na educação infantil. Revista Brasileira de Extensão Universitária, 11(2), 113-124. https://periodicos.uffs.edu.br/index.php/RBEU/article/view/ 10857/pdf 